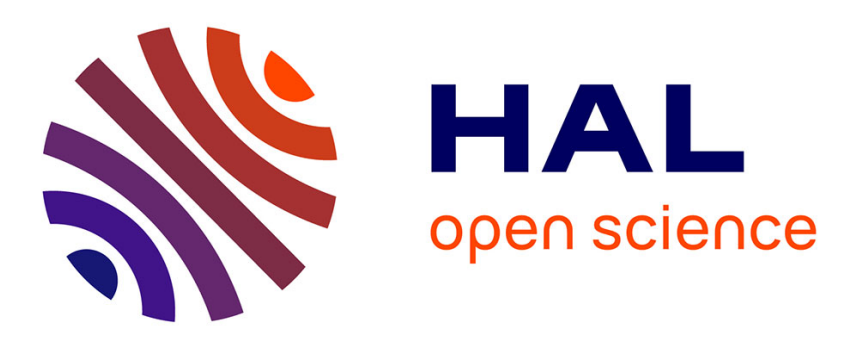

\title{
Dynamic network based on eugenol-derived epoxy as promising sustainable thermoset materials
}

Connie Ocando, Yvan Ecochard, Mélanie Decostanzi, Sylvain Caillol, Luc

Avérous

\section{- To cite this version:}

Connie Ocando, Yvan Ecochard, Mélanie Decostanzi, Sylvain Caillol, Luc Avérous. Dynamic network based on eugenol-derived epoxy as promising sustainable thermoset materials. European Polymer Journal, 2020, 135, pp.109860. 10.1016/j.eurpolymj.2020.109860 . hal-02897377

\section{HAL Id: hal-02897377 \\ https://hal.science/hal-02897377}

Submitted on 11 Jul 2020

HAL is a multi-disciplinary open access archive for the deposit and dissemination of scientific research documents, whether they are published or not. The documents may come from teaching and research institutions in France or abroad, or from public or private research centers.
L'archive ouverte pluridisciplinaire HAL, est destinée au dépôt et à la diffusion de documents scientifiques de niveau recherche, publiés ou non, émanant des établissements d'enseignement et de recherche français ou étrangers, des laboratoires publics ou privés. 


\section{Dynamic network based on eugenol-derived epoxy as promising sustainable thermoset materials}

Connie Ocando* ${ }^{\dagger}$ [a], Yvan Ecochard [b], Mélanie Decostanzi [b], Sylvain Caillol [b], and Luc Avérous * [a]

[a] BioTeam/ICPEES-ECPM, UMR CNRS 7515, Université de Strasbourg, Strasbourg Cedex 2, France.

[b] Institut Charles Gerhardt, UMR 5253 - CNRS, Université de Montpellier, Ecole Nationale Supérieure de Chimie de Montpellier, 8 rue de l'Ecole Normale, 34296 Montpellier, France.

\section{KEYWORDS}

Thermoset, eugenol, disulfide exchange, dynamic crosslink, self-healing, reshaping, recycling.

ABSTRACT Permanently crosslinked polymer networks, such as fully cured thermosets derived from fossil-based epoxies, cannot be reuse after damage and/or recycled since they cannot be reprocessed by heating or solubilization as non-crosslinked thermoplastics. As a result, they are not really sustainable materials, generating non-renewable resources consumption, $\mathrm{CO}_{2}$ emissions and plastic pollution. Herein we employed a strategy to tackle the lack of sustainability in conventional thermosets by the development of a promising partially biobased epoxy for numerous applications, integrating a covalent adaptable network using associative dynamic chemistry and catalyst free mechanism. This strategy is based in two sustainable 
approaches. First, vegetal biomass has been used as a renewable resource for the synthesis of epoxy systems from epoxidized eugenol oil. Then, the crosslinking reaction with an diamine integrating disulfide bonds to attain a thermally induced reorganizable eugenol-derived epoxy network in a dynamic way by disulfide metathesis reaction. The viscoelastic behavior characterization of eugenol-derived epoxy network displays a fast macroscopic flow with a stress relaxation time of $37 \mathrm{~s}$ at $230{ }^{\circ} \mathrm{C}$, suggesting an interesting melt-reprocessability of this network at high temperatures in short times. Moreover, this strategy has a strong potential for the progress of sustainable plastic applications as yield a synthetic procedure to develop stiff thermosets (storage modulus of around $1 \mathrm{GPa}$ at glassy state) with high renewable carbon contents (around $70 \mathrm{wt} \%$ ), enhanced thermal properties $\left(\mathrm{T}_{\mathrm{g}}\right.$ of around $\left.190^{\circ} \mathrm{C}\right)$ and additional properties such as promising reshaping, repairing and recycling capability.

\section{Introduction}

Nowadays, the entire value chain associated to polymers, in particular thermosetting polymers, is facing a rough scrutiny for its negative impacts in the economy and the environment. The global commitment to tackle these negative impacts involve that all plastic must be reused and/or recycled. Therefore, an efficient physical reprocessing strategy is necessary in order to stop the waste disposal into the environment, the consumption of non-renewable resources and $\mathrm{CO}_{2}$ emissions. As a result, contribute achieving the EU Product Policy Framework of the Circular Economy targets.

Compared with non-crosslinked thermoplastics, thermosetting polymers present a large range of engineered advantages. Thermosetting polymers are nowadays widely used as adhesives, electrical castings, flooring and paving applications as well as matrices for structural performing 
composites and foams. They globally represent $15-20 \%$ of plastics manufacture [1]. Among them, epoxy resins are of great economic importance as they represent around $70 \%$ of thermosets global market without including polyurethanes [2]. The development of more sustainable thermosetting epoxy materials with an improved LCA is a strong challenge nowadays. Then, to improve the environmental impact from cradle to grave, the properties and the behavior of this type of materials, two main ways can be underway and coupled (i) Developing more sustainable approaches during the synthesis (ii) Developing materials with an improved ends of life, in order that they can be reshaped, repaired or recycled after usage or damage.

For instance, dynamic covalent networks [3, 4] such as vitrimers [5-14] have been recently established as an innovative and new class of polymer that are characterized by a crosslinked network that when it is heated at a certain temperature it can flow without depolymerization. This behavior is due to the occurrence of thermally activated crosslink exchange reactions of the network in an associative manner without a decrease on the crosslink density, retaining the 3D cross-linked structure. Vitrimers are able to undergo a rearrangement of the initial network topology by the breaking of a covalently crosslinked bond followed by the instant creation of a new covalent bond in other position of the polymer chain. In this context, this type of dynamic crosslinked system allows the material to flow at high temperatures and to be reprocessed.

It has been found that one effective strategy to confer reprocessing capabilities to a fossilbased thermosetting polymer is to introduce disulfide-containing amines within the polymer network [15-23]. The proposed strategy allowed that the thermosetting polymer undergo a network rearrangement while the 3D structure is maintained without a sudden drop in viscosity. Hence, in terms of applications this strategy is more adequate than the reversible and dissociative approach of e.g, the well-known Diels-Alder reaction. This highlighted disadvantage is because 
through the Diels-Alder strategy the crosslinked network depolymerizes and as result an undesirable loss of the polymer stability is obtained [24-26].

Besides, most of the studies on polymeric vitrimers and dynamic networks have been performed from fossil-based epoxies that have hazardous effects on human health and ecotoxicity. Therefore, the exploitation of renewable resources, such as plant oils [27], is necessary and timely from both academic and industrial points of view, with the sustainable development of epoxidized precursors in line with the criteria established by the new EU chemical regulations, RoHS and REACh [2]. These epoxidized precursors can be used in the synthesis of partially or fully biobased thermosetting polymers with improve thermomechanical properties. For instance, aromatic epoxidized oils such as cardanol [28, 29], soybean [30] and eugenol [31-34] have been reported as proper renewable substitutes of DGEBA. Nevertheless, chemically cross-linked plant-derived epoxy resins are also nonrecyclable.

On the basis of literature research, recently, an eugenol-derived epoxy (Eu-EP) has been reported $[32,34]$ with reshaping, self-healing, and shape memory properties prepared by reacting Eu-EP with succinic anhydride at various ratios in presence of zinc-based catalysts. On the other hand, a metal-catalyzed ESO-based vitrimer was prepared using fumaropimaric acid as a curing agent and zinc acetylacetonate as the transesterification catalyst [35]. Besides, a biobased thermosetting vitrimer from isosorbide-derived epoxy and aromatic diamine containing disulfide bonds has been reported [36]. Nevertheless, these two latter biobased vitrimers did not exhibit thermomechanical properties that are comparable or superior to the well-established fossil-based DGEBA. Hence, the investigation of environmentally friendly alternatives for the development of biobased epoxy with dynamic networks that are in continuous advancement still remains a challenge for a more sustainable polymer industry. 
The objective of the current work is the development of a partially biobased aromatic material from eugenol that can be reshapeable, self-healable and recyclable by means of associative dynamic chemistry without catalysts on agreement with principles for a green chemistry. Thermosetting polymers based on synthetized tri(epoxized-eugenyl) phosphate (TEEP) were prepared. Epoxidized eugenol was selected as the thermosetting matrix to confer high modulus and thermal properties compared with fossil-based DGEBA [37]. A disulfide-containing amine was applied as a curing agent.

\section{Experimental Section}

\section{Materials}

Eugenol (99\%), phosphorus oxychloride (99\%), triethylamine (99\%), 3-chloroperbenzoic acid (77\%), 4-aminophenyl disulfide, DSA (98\%) were purchased from Sigma Aldrich France. 3,3'diaminodiphenyl sulfone, DDS (98\%) was purchased from Alfa Aesar.

Synthesis of trieugenylphosphate (TEP)

First, a mixture of eugenol $(61 \mathrm{mmol})$ and triethylamine $(61 \mathrm{mmol})$ in ethyl acetate $(100 \mathrm{~mL})$ was prepared and phosphorus oxychloride $(20.33 \mathrm{mmol})$ was added drop by drop at temperatures between 0 and $5^{\circ} \mathrm{C}$. The mixture was maintained between 0 and $5^{\circ} \mathrm{C}$ during $30 \mathrm{~min}$, and then it was stirred at room temperature during16 hours. Afterwards, the mixture was diluted by adding $100 \mathrm{~mL}$ of ethyl acetate and washed several times with $100 \mathrm{~mL}$ of deionized (DI) water and one time with $100 \mathrm{~mL}$ brine solution. The organic portion was then dried with anhydrous magnesium sulfate and filtered. Finally, the filtrate was distilled under vacuum. The detailed synthesis of TEP and the corresponding characterizations have been previously reported by Caillol et al. [31]. 
Synthesis of tri(epoxized-eugenyl)phosphate (TEEP)

First a suspension of meta-chloroperbenzoïc acid (m-CPBA 77\%) $(62.7 \mathrm{mmol})$ in $200 \mathrm{~mL}$ of ethyl acetate was added drop by drop to a solution of TEP $(19 \mathrm{mmol})$ in $50 \mathrm{~mL}$ of ethyl acetate at temperatures between 0 and $5^{\circ} \mathrm{C}$. The resulted mixture was maintained at this rage of temperature during $30 \mathrm{~min}$, and then it was stirred at room temperature during 24 hours. Afterwards, the solvent in the mixture was evaporated and the excess of m-CPBA was neutralized with a saturated solution of sodium bicarbonate and removed with ethyl acetate. The organic part was washed several times with saturated sodium bicarbonate, brine and deionized water. The organic part was dried with anhydrous magnesium sulfate and filtered. Finally, the filtrate was distilled under vacuum. The detailed synthesis of TEEP has been previously reported by Caillol et al. [31].

Preparation of partially biobased epoxy networks:

a-Partially biobased epoxy network from tri(epoxized-eugenyl)phosphate cured with the dynamic crosslinker (TEEP:DSA)

A eugenol based epoxy system containing exchangeable crosslinks in a dynamic way was prepared by vigorously mixing the TEEP and DSA in a stoichiometric weight ratio (epoxy: $\mathrm{N}-\mathrm{H}=1: 1$ ) at $12{ }^{\circ} \mathrm{C}$ during $3 \mathrm{~min}$ to form a viscous homogeneous mixture. Immediately, the reaction mixture was casted into a preheated Teflon mold of $24 \times 5 \times 1 \mathrm{~mm}^{3}$ at $120^{\circ} \mathrm{C}$, and then hot pressed for $3000 \mathrm{sec}$ at 20 bar. Afterwards the parallelepiped samples were transferred into an oven to continue curing at $120^{\circ} \mathrm{C}$ for $1 \mathrm{~h}$ and at $150{ }^{\circ} \mathrm{C}$ for $2 \mathrm{~h}$ and post-cure at 180 for $2 \mathrm{~h}$. Solvent casted films were also prepared. 
b- Partially biobased epoxy network from tri(epoxized-eugenyl)phosphate cured with the nonreversible crosslinker (TEEP:DDS)

A eugenol based epoxy system containing non-reversible chemical bonds was prepared by vigorously mixing TEEP and DDS in a stoichiometric weight ratio (epoxy: $\mathrm{N}-\mathrm{H}=1: 1$ ) at $150{ }^{\circ} \mathrm{C}$ during $1 \mathrm{~min}$ to form a viscous homogeneous mixture. Immediately, the reaction mixture was casted into a preheated Teflon mold of $24 \times 5 \times 1 \mathrm{~mm}^{3}$ at $150{ }^{\circ} \mathrm{C}$ and hot pressed for $3000 \mathrm{sec}$ at 20 bar. Afterwards the parallelepiped samples were transferred to an oven to continue curing at 150 ${ }^{\circ} \mathrm{C}$ for $2 \mathrm{~h}$ and post-cure at 180 for $2 \mathrm{~h}$. Solvent casted films were also prepared.

Fourier transformed infrared (FTIR)

A blank background was carried out before examining the samples (32 scans were accumulated at a resolution of $4 \mathrm{~cm}^{-1}$ ) on a Nicolet 380 spectrometer equipped with an ATR diamond module in reflection mode.

Differential scanning calorimetry (DSC)

The glass transition temperature $\left(\mathrm{T}_{\mathrm{g}}\right)$ of the bio-based epoxy networks before and after curing reaction was determined using a DSC Q 200 (TA Instruments) by scanning the sample (around 3 $\mathrm{mg}$ ) from 25 to $230{ }^{\circ} \mathrm{C}$ at a heating rate of $10^{\circ} \mathrm{C} / \mathrm{min}$ under nitrogen flow $(50 \mathrm{~mL} / \mathrm{min})$.

Gel content

The gel content of all partially biobased epoxy networks was determined by the solvent extraction method using THF. The sample was weighted and immersed in THF at room temperature during $72 \mathrm{~h}$. Afterwards the sample was dry at $70^{\circ} \mathrm{C}$ in an oven and under vacuum until there was no appreciable weight change. The gel content was calculated using the following equation:

$$
G C=\left(\frac{m_{2}}{m_{1}}\right) \times 100
$$


where $\mathrm{m}_{2}$ is the mass of the sample after drying and $\mathrm{m}_{1}$ is the initial mass of the sample.

Thermogravimetric analysis (TGA)

TGA experiments of the biobased epoxy networks were carried out on a TGA Q 5000 apparatus (TA Instruments), from room temperature to $700{ }^{\circ} \mathrm{C}$ at a heating rate of $20{ }^{\circ} \mathrm{C} / \mathrm{min}$ under inert atmosphere to avoid oxidative thermal degradation.

Dynamic mechanical analysis (DMA) and Isothermal stress relaxation

The dynamic mechanical properties of the biobased epoxy networks were characterized using a Discovery HR hybrid rheometer (TA instruments) in torsion mode to determine the storage modulus $\left(\mathrm{G}^{\prime}\right)$, loss factor $(\tan \delta)$, and the mechanical transition temperatures $\left(\mathrm{T}_{\alpha}\right)$. The dimension of the sample was $24 \times 5 \times 1 \mathrm{~mm}^{3}$. The frequency was set at $1 \mathrm{~Hz}$, and the torsional dynamic strain was set at $0.05 \%$. The value of torsional dynamic strain used was determined by a previous strain sweep experiment to determine the region of linear response where G' was constant. The samples were scanned from 30 to $230{ }^{\circ} \mathrm{C}$ at $5^{\circ} \mathrm{C} / \mathrm{min}$. For the isothermal stress relaxation experiments, a torsional strain of $0.1 \%$ was applied and the stress relaxation modulus was monitored as a function of time at temperatures of $130,200,210$ and $230{ }^{\circ} \mathrm{C}$. When the equipment reached the testing temperature, the sample was allowed to achieve thermal equilibrium during 10 min before measuring.

Crosslinking density

The crosslinking density of TEEP:DSA and TEEP:DDS after post-curing was calculated from DMA results using the following equation [REFERENCE.]:

$$
\text { Crosslinking density }=\frac{G^{\prime}}{3 T R}
$$


where $\mathrm{G}^{\prime}$ is the storage modulus $(\mathrm{MPa})$, on the rubbery plateau $\left(230^{\circ} \mathrm{C}\right), \mathrm{T}$ is the temperature in kelvin, $\mathrm{R}$ is the universal gas constant $\left(8.314 \mathrm{MPa} . \mathrm{cm}^{3} / \mathrm{mol} \mathrm{K}\right)$.

Reshaping test

To assess the potential reshaping properties of fully cured partially biobased epoxy network containing dynamically reversible crosslinks, a flat film of TEEP:DSA was covered in Teflon tape and bent over a glass cylinder to take a new shape. Afterwards, this bent-shaped film was heated in an oven at $230^{\circ} \mathrm{C}$ for $1 \mathrm{~h}$, the film was finally cooled down to room temperature. In order to confirm the stability of the new shape, a shape memory test was carried out. For shape memory testing, the following deformation-fixation-relaxation cycle was performed: 1) the Ushaped film was heated at $180{ }^{\circ} \mathrm{C}$ for about $60 \mathrm{~s}$, 2) the film was then manually deformed to be flat again and cooled at ambient condition until the temporary shape was fixed. 3) The specimen with temporary flat shape was then reheated at $180{ }^{\circ} \mathrm{C}$ to examine the shape recovery. The inner diameter as well as the curvature of the deformed specimens were quantified. The recovered angle ( $\theta r$, recorded by drawing the tangents at the two edges of recovered samples) was recorded, and the recovery ratio $(\mathrm{Rr})$ was calculated by $\theta \mathrm{r} / 180^{\circ} \mathrm{x} 100 \%$.

\section{Self-healing test}

In order to demonstrate the potential healing properties with temperature of the partially biobased epoxy network containing dynamically reversible crosslinks, a TEEP:DSA film was scratched with a razor blade to create a visible crack on the surface by Optical Microscopy (OM). The healing process was performed at $230{ }^{\circ} \mathrm{C}$ in a hot plate and the aspect of the film surface was recorded before and after treatment by OM.

Solid-state recycling test 
The potential recycling capability of the fully cured biobased epoxy network containing dynamically reversible crosslinks, TEEP:DSA, was demonstrated by welding two small pieces. A small area of the two pieces were superimposed and join together in a hot press at $200{ }^{\circ} \mathrm{C}$ for $3000 \mathrm{sec}$ at 20 bar. After the sample was press released and cooled down to room temperature.

\section{Results and Discussion}

TEEP:DSA and TEEP:DDS partially biobased epoxy systems were prepared through a twostep synthesis pathway. First, a trieugenylphosphate (TEP) was synthesized by treating eugenol with phosphorus oxychloride. Afterwards, the allylic groups of TEP were epoxidized with mCPBA to obtain tri(epoxized-eugenyl)phosphate (TEEP). The physicochemical characterization of TEP and TEEP has been previously reported by Caillol et al. [31], corroborating the disappearance of $\mathrm{OH}$ groups of eugenol by the reaction with phosphorus oxychoride to develop the TEP building block as well as the conversion of the double bonds in the TEP for epoxy groups to develop the TEEP bio-based resin. The second step consisted in the generation of the different partially biobased epoxy networks by the thermal curing of the epoxidized precursor with the dynamic (DSA) and non-dynamic crosslinker (DDS) (Scheme 1).

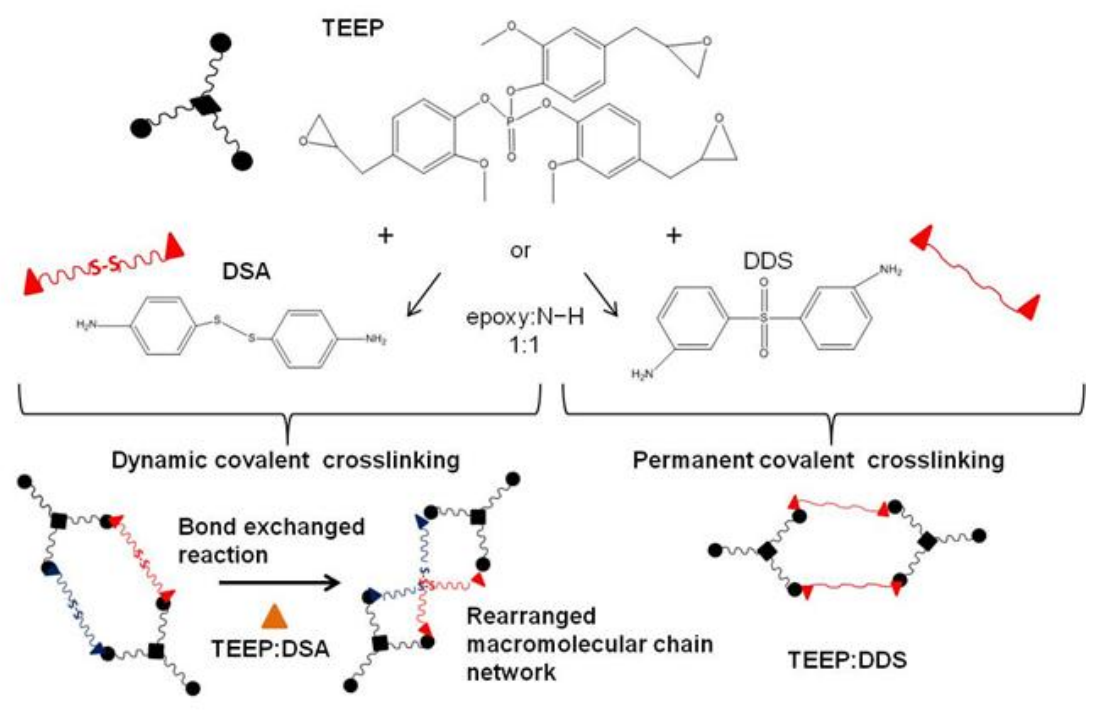

Scheme 1. General overview of the synthesis of the different partially biobased epoxy networks. 
The crosslinking reaction of TEEP:DSA system was studied by DSC in order to stablish the proper curing protocol. As can be seen from table 1 and figure 1, the epoxy system began to cure at around $100{ }^{\circ} \mathrm{C}$ with a maximum curing temperature at around $185^{\circ} \mathrm{C}$. In this sense, the postcuring protocol was set at 180 for $2 \mathrm{~h}$. An increment of $\mathrm{T}_{\mathrm{g}}$ was observed, from $7{ }^{\circ} \mathrm{C}$ for the uncured system to $193^{\circ} \mathrm{C}$ for the post-cured system, corroborating the epoxy network formation. In addition, full crosslinking of TEEP:DSA after post-curing at $180{ }^{\circ} \mathrm{C}$ for $2 \mathrm{~h}$ was confirmed by the disappearance of the exothermic peak at high temperatures and also because the $T_{g}$ of the system remained invariable in the second heating scan.

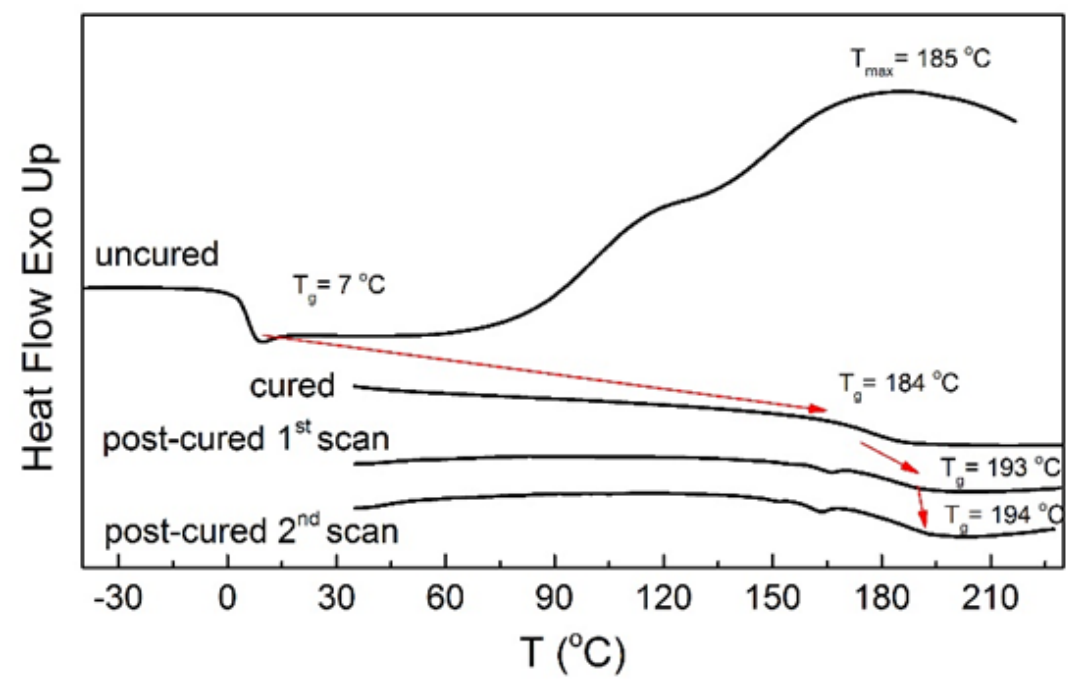

Figure 1. DSC heating scans at $10{ }^{\circ} \mathrm{C} / \mathrm{min}$ of of uncured, cured and post-cured TEEP :DSA partially biobased epoxy systems.

Table 1. Thermal properties of uncured, cured and post cured TEEP:DSA partially biobased epoxy systems.

\begin{tabular}{|c|c|c|c|c|}
\hline Sample & $\begin{array}{c}\mathbf{T}_{\mathbf{g}} \\
\text { uncured } \\
\text { system }^{(\mathbf{a})} \\
\left({ }^{\circ} \mathbf{C}\right) \\
\end{array}$ & $\begin{array}{c}\mathbf{T}_{\mathbf{g}} \\
\text { cured }^{(\mathbf{b})} \\
\text { system }^{(\mathbf{b})} \\
\left({ }^{\circ} \mathbf{C}\right) \\
\end{array}$ & $\begin{array}{c}\mathbf{T}_{\mathrm{g}} \\
\text { post-cured } \\
\text { system }^{(\mathrm{c})} \\
\left({ }^{\circ} \mathrm{C}\right) \\
\end{array}$ & $\begin{array}{c}\mathbf{T}_{\mathbf{g}} \\
\text { post-cured } \\
\text { system }^{(\mathbf{d})} \\
\left({ }^{\circ} \mathbf{C}\right) \\
\end{array}$ \\
\hline TEEP:DSA & 7 & 184 & 193 & 194 \\
\hline
\end{tabular}

(a) $\mathrm{T}_{\mathrm{g}}$ value (endset point) obtained from the first heating scan at $10^{\circ} \mathrm{C} / \mathrm{min}\left(-50-200^{\circ} \mathrm{C}\right)$

(b) $\mathrm{T}_{\mathrm{g}}$ value (endset point) obtained from the first heating scan at $10^{\circ} \mathrm{C} / \mathrm{min}\left(25-230^{\circ} \mathrm{C}\right)$

(c) $\mathrm{T}_{\mathrm{g}}$ value (endset point) obtained from the first heating scan at $10^{\circ} \mathrm{C} / \mathrm{min}\left(25-230^{\circ} \mathrm{C}\right)$

(d) $\mathrm{T}_{\mathrm{g}}$ value (endset point) obtained from the second heating scan at $10^{\circ} \mathrm{C} / \mathrm{min}\left(25-230^{\circ} \mathrm{C}\right)$ 
The crosslinking reaction was also corroborated by FTIR. Figure S2 shows the FTIR spectra for TEEP:DSA before and after curing at $120{ }^{\circ} \mathrm{C}$ for $1 \mathrm{~h}$ and at $150{ }^{\circ} \mathrm{C}$ for $2 \mathrm{~h}$ and post-cure at 180 for $2 \mathrm{~h}$. As can be seen, the signals of stretching C-O-C at $850 \mathrm{~cm}^{-1}$ and stretching of C-H of the oxirane ring at $3057 \mathrm{~cm}^{-1}$ disappeared, demonstrating the formation of the epoxy network of TEEP:DSA.
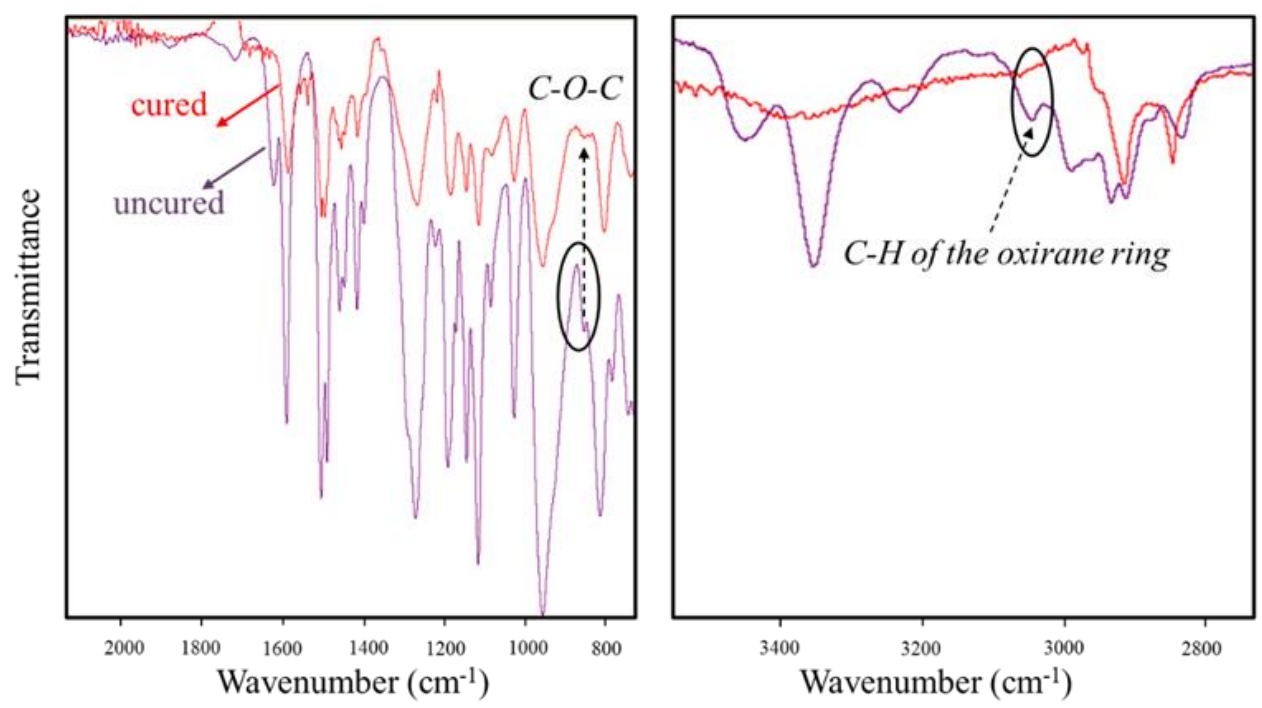

Figure 2. FTIR spectra of uncured and cured TEEP :DSA partially biobased epoxy systems.

\section{Thermal characterization and gel content evaluation of cured partially biobased epoxy} systems after curing.

First, the efficiency of the curing reaction of all the biobased epoxy systems was evaluated by gel content estimation using the solvent extraction method. Table 1 shows that high gel content values in THF were obtained for all the partially biobased epoxy networks indicating that the synthetized thermosets were effectively crosslinked. No appreciable weight loss was detected after the solvent extraction. 
Table 2. Thermal stability and gel content of TEEP:DSA and TEEP:DDS partially biobased epoxy systems.

\begin{tabular}{lllll}
\hline Sample & Gel content & $\mathbf{T}_{\mathbf{d}, \mathbf{5} \%}$ & $\mathbf{T}_{\mathbf{d}, \text { peak }}$ & $\begin{array}{l}\text { Residual } \\
\text { yield }\end{array}$ \\
& $(\mathbf{\%})$ & $\left({ }^{\circ} \mathbf{C}\right)$ & $\left({ }^{\circ} \mathbf{C}\right)$ & \begin{tabular}{l}
$\left({ }^{\circ} \mathbf{C}\right)$ \\
\hline TEEP:DSA
\end{tabular} \\
TEEP:DDS & 99 & 295 & 327 & 55 \\
\hline
\end{tabular}

(a) Residual yield after TGA at $700^{\circ} \mathrm{C}$ in nitrogen atmosphere

Figure S1 shows the thermograms for both partially biobased epoxies after post-curing. All degradation temperatures are presented Table 2. The degradation temperatures selected for the evaluation are at 5 wt.\% of weight loss and at the maximum degradation temperature. The maximum degradation temperature is related with the maximum peak of the derivative of the weight loss. As can be seen, the thermal decomposition of TEEP:DSA and TEEP:DDS did not show weight loss higher than $5 \mathrm{wt} \%$ at temperatures up to $290{ }^{\circ} \mathrm{C}$. The onset thermal decomposition of both partially biobased epoxy networks has been ascribed to the chemical breakage of the methoxy groups from eugenol chains [34]. As can be seen, TEEP:DSA showed a slightly lower degradation temperature than TEEP:DDS. This behavior can be ascribed to the presence of less stable disulfide bonds in contrast with $\mathrm{C}-\mathrm{C}$ bonds [36]. Interestingly, all the partially biobased epoxy networks begin to degrade above around $100{ }^{\circ} \mathrm{C}$ from their corresponding $\mathrm{T}_{\mathrm{g}}$, a good indicative that TEEP:DSA epoxy networks can be reprocessed at high temperatures. It is a key point for vitrimer applications as covalent adaptable networks triggered by temperature. On the other hand, all the systems showed high residual yield values after summit the samples at $700^{\circ} \mathrm{C}$. From table 1 , it can be pointed out that the thermal stability and residual yield of the biobased epoxies depend mainly on the phosphorus content [37]. On the 
basis of literature research [34], residual yield of $13.8 \mathrm{wt} \%$ has been found for DGEBA:DDS by means of thermogravimetric analytical curves up to $800{ }^{\circ} \mathrm{C}$ under $\mathrm{N}_{2}$, meaning a four times increment for TEEP:DDS $(58 \mathrm{wt} \%)$ respect to fossil-based DGEBA:DDS. Hence, these developed partially biobased epoxy networks are suitable materials for applications where fire retardant property is required, such as structural materials for aerospace and transportation.

\section{Dynamic mechanical properties of partially biobased epoxy systems.}

The stiffness and damping properties of the fully cured partially biobased epoxy networks were evaluated by torsional dynamic strain experiments in order to follow the temperature dependence of the storage modulus $\left(\mathrm{G}^{\prime}\right)$ and loss tangent $(\tan \delta)$ of TEEP:DSA and TEEP:DDS. DMA spectra are shown in Figure 3 (a) and (b). The values of the thermomechanical properties for each partially biobased epoxy network are summarized in Table 3. The reported mechanical relaxation temperatures $\left(\mathrm{T}_{\alpha}\right)$ were taken at the maximum of the $\tan \delta$ peak and then associated to the glass transition temperature $\left(\mathrm{T}_{\mathrm{g}}\right)$.

Table 3. Thermomechanical properties of TEEP:DSA and TEEP:DDS partially biobased epoxy systems.

\begin{tabular}{ccccc}
\hline Sample & $\begin{array}{c}\mathrm{G}^{\prime} \\
\text { at } 35^{\circ} \mathrm{C}(\mathrm{Pa})\end{array}$ & $\begin{array}{c}\mathrm{G}^{\prime} \\
\text { at } 230^{\circ} \mathrm{C}(\mathrm{Pa})\end{array}$ & $\begin{array}{c}\mathrm{T}_{\alpha} \\
\left({ }^{\circ} \mathrm{C}\right)\end{array}$ & $\begin{array}{c}\text { Crosslink density } \\
\left(\mathrm{mol} / \mathrm{cm}^{3}\right)\end{array}$ \\
\hline TEEP:DSA & $9.28 \mathrm{E} 8$ & $5.73 \mathrm{E} 7$ & 192 & 0.00457 \\
TEEP:DDS & $1.24 \mathrm{E} 9$ & $5.75 \mathrm{E} 7$ & 197 & 0.00459 \\
\hline
\end{tabular}




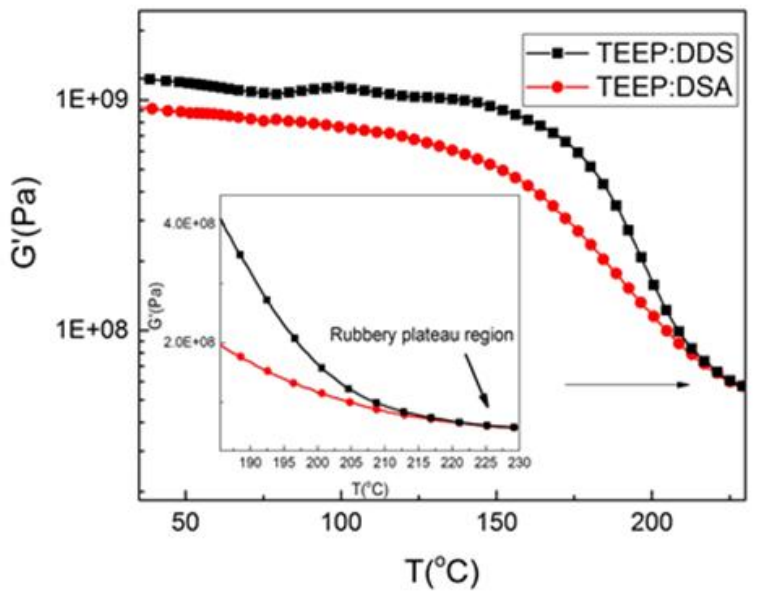

(a)

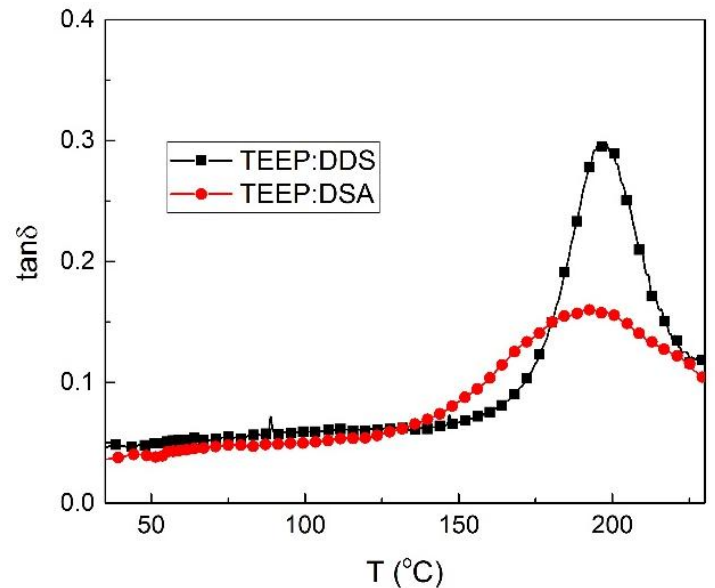

(b)

Figure 3. DMA spectra for the storage modulus (G') (a) and loss factor (tan $\delta$ ) (b) versus temperature of TEEP:DSA and TEEP:DDS partially biobased epoxy systems.

From DMA spectra, it can be concluded that the stoichiometric formulation used to prepare all the systems, with a high renewable carbon content of around $70 \mathrm{wt} . \%$, permits the development of partially biobased epoxy networks with higher $T_{\alpha}$ and comparable stiffness than that of conventional fossil-based systems. For instance, Odriozola et al. [21] have obtained $\mathrm{T}_{\alpha}$ at around $130^{\circ} \mathrm{C}$ for the fossil-based DGEBA cured with DSA in a stoichiometric weight ratio. The high $\mathrm{T}_{\alpha}$ values in the partially biobased epoxy systems from this work compared with fossil-based DGEBA cured with DSA are due to a higher oxirane functionality in the TEEP monomer compared to DGEBA monomer. On the other hand, the value of storage modulus at glassy state of TEEP:DSA and TEEP:DDS were comparable with the value of DGEBA:DDS found in the literature [38]. As expected, identical crosslinking density was obtained for TEEP:DDS and TEEP:DSA due to the similarity in the molar mass, length and chemical architecture of the dynamic and non-dynamic cross-linkers, this result is in agreement with the gel content reported for TEEP:DDS and TEEP:DSA in table 2. 


\section{Thermal stress relaxation of disulfide exchange reactions of partially biobased epoxy}

\section{systems.}

The time-dependent shear stress at various temperatures was monitored for TEEP:DSA and TEEP:DDS by steady strain experiment using a rheometer in torsion mode. This test was carried out in order to study the capability of the partially biobased epoxy system cured with the dynamic crosslinker to be malleable and thermally reprocessed. The evaluated temperatures were selected in order to be above and below the corresponding $\mathrm{T}_{\alpha}$. This procedure allowed establishing the appropriate activation temperature and rate of cross-link reorganization in the dynamic covalent network [39]. It is expected that the disulfide chemical bonds present in the epoxy network can exchanged efficiently between different positions of the polymer chains at a specific temperature. For this purpose, the strain was maintained at a fixed value to monitor the viscoelastic behavior of the material by measuring the thermal stress relaxation with the time. The Maxwell model for viscoelastic fluids was applied in order to define the stress relaxation time $\left(\mathrm{t}^{*}\right)$ for each temperature. The model outlines that the time for stress relaxation is the time needed for the modulus to fall to $1 /$ e of its initial value, in other words $G_{(t)} / G_{0}=0.37$, where $G_{(t)}$ is the value of relaxed modulus at a fixed time and $\mathrm{G}_{0}$ is the unrelaxed modulus. The Arrhenius equation was employed to evaluate the minimum energy to start disulfide bond exchange reactions $(\mathrm{Ea})$, as follow:

$$
\tau *=\tau_{0} \exp \left(\frac{\mathrm{Ea}}{\mathrm{RT}}\right)[3]
$$

where $\tau^{*}$ is the relaxation time, $\tau_{0}$ is the characteristic relaxation time, Ea is the activation Energy, $\mathrm{R}$ is the gas constant and $\mathrm{T}$ is the temperature. 
Table 4. Relaxation times $\left(\tau^{*}\right)$, activation energy (Ea), and topology freezing temperature (Tv) of TEEP:DDA.

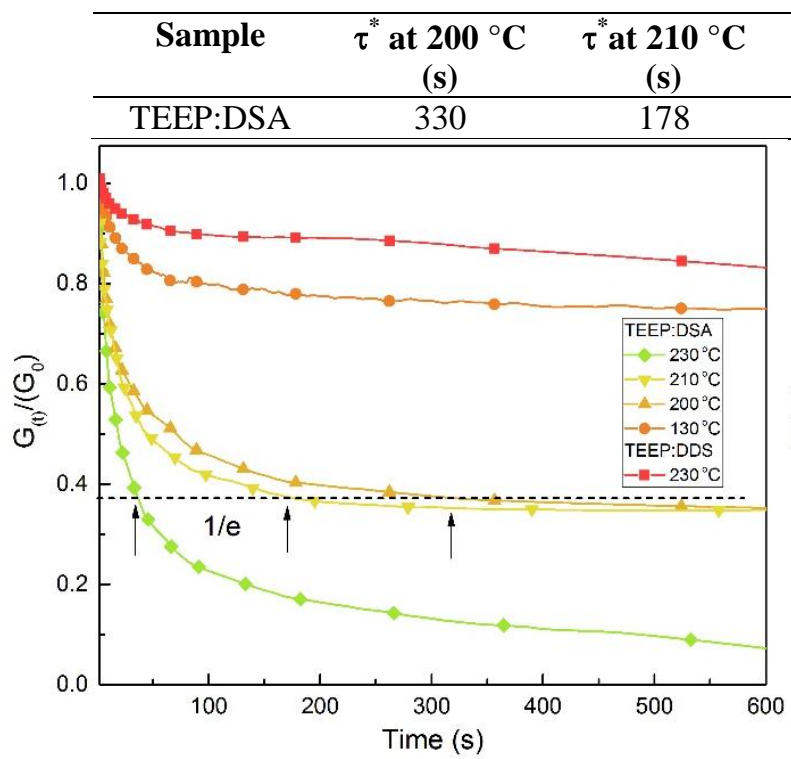

(a)

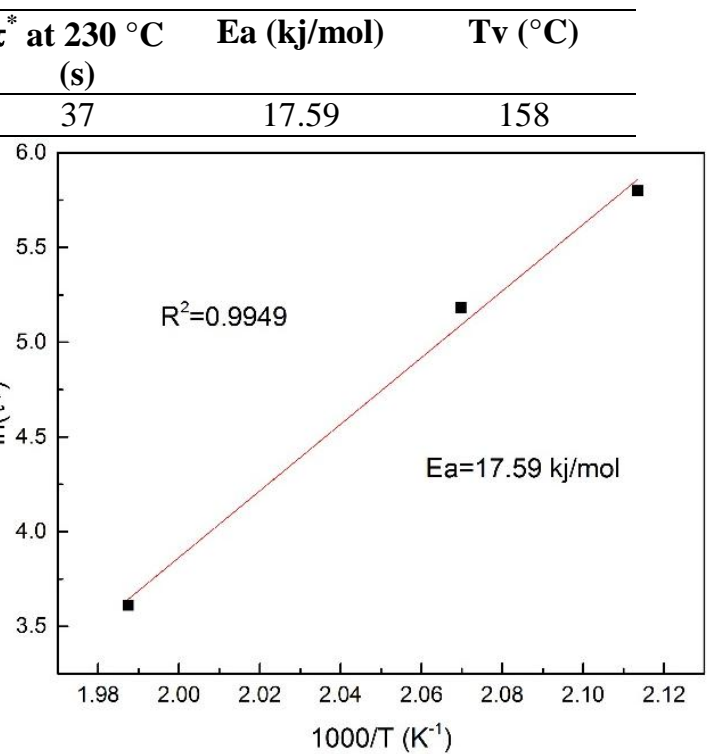

(b)

Figure 4. Evolution of normalized relaxation modulus, $\mathrm{G}_{(\mathrm{t})} / \mathrm{G}_{0}$, for TEEP:DSA and TEEP:DDS at different temperatures. The dotted line shows the characteristic relaxation time (a) and Arrhenius analysis of the characteristic relaxation time $\tau^{*}$ versus 1000/T (b).

As can be seen from Figure 4 and table 4, the relaxation time of TEEP:DSA decreased with temperature according to the Arrhenius law (equation 3), confirming the vitrimeric behaviour of this system with a disulfide bonds exchange activation energy-dependence (Ea) of around 17 $\mathrm{kJ} / \mathrm{mol}$ (calculated from the slope of the Arrhenius plot obtained from the relaxation times $\tau^{*}$ at diff erent temperatures). As a result, the time-dependent shear stress shows a macroscopic flow without permanent loss of material properties. The observed stress relaxation time was around 37 $\mathrm{s}$ at $230^{\circ} \mathrm{C}$, corresponding to a fast disulfide bond exchange rate due to an increase in the segmental mobility at a temperature around $40{ }^{\circ} \mathrm{C}$ higher than the $\mathrm{T}_{\alpha}$. The fast stress relaxation obtained for TEEP:DSA is in the range of the fastest stress relaxation time reported for rigid and 
highly cross-linked materials [REFERENCES]. At $130{ }^{\circ} \mathrm{C}$, temperature bellow the $\mathrm{T}_{\alpha}$ of the system, it was not observed a considerable drop in the modulus even after $3600 \mathrm{~s}$ of testing, because this temperature was not higher enough to induce segmental motions in the epoxy network and as consequence the disulfide bonds are frozen. This behavior at $130{ }^{\circ} \mathrm{C}$ can be explained with the estimation of the hypothetical topology freezing temperature $\left(T_{v}\right)$ that is the temperature in which the material experience a transition from solid to liquid due to a bond exchange reaction in a dynamic network, and this transition is assumed to occur when the viscosity becomes higher than $10^{12}$ Pa.s [REFERENCES]. In this sense, a $T_{v}$ value of around 151 ${ }^{\circ} \mathrm{C}$ (bellow the $\mathrm{T}_{\alpha}$ ) was theoretically determined by the estimation of $\tau^{*}$ with the Maxwel equation (equation 4) and the extrapolation of the Arrhenius' fitted line at the estimated $\tau^{*}$.

$$
\eta=\mathrm{G} \cdot \tau *[4]
$$

where, $\eta$ is the viscosity $\left(10^{12}\right.$ Pa.s $), G$ is the shear viscosity modulus $\left(G=G^{\prime} /(2(1+v))\right.$, with $v$ $\approx 0.5$, the Poisson's ratio and $\tau *$ is the relaxation time.

The macroscopic flow observed for TEEP:DSA at $230{ }^{\circ} \mathrm{C}$ on very short time is a prove that this partially biobased epoxy can be heat-processable like thermoplastics in order to be reshaped, healed and even recycled by the welding of fragmented pieces. In addition, an isotherm weight loss experiment carried out by TGA at $230^{\circ} \mathrm{C}$ under oxidative air atmosphere during $1 \mathrm{~h}$ showed a weight loss of only around $2 \%$. Indicating a good thermal stability during a reshaping, healing and recycling processes.

On the other hand, it was observed that TEEP:DDS did not show stress relaxation at $230^{\circ} \mathrm{C}$, corroborating that the macroscopic flow was only possible in the epoxy network able to carried out disulphide exchange reactions. 


\section{Reshaping tests of partially biobased epoxy systems.}

To study the reshaping ability of the partially biobased epoxy system containing the dynamic crosslinker, a flat film of TEEP:DSA was reshaped in order to it takes a new permanent bentshape configuration. As can be seen in Figure 5, the TEEP:DSA film successfully changed its shape after the thermal treatment at $230^{\circ} \mathrm{C}$, a temperature above its $\mathrm{T}_{\alpha}$ or activation temperature. This ability can be explained by the thermally induced dynamic exchange reaction of disulfide bonds that cause the rearrangement of the covalent crosslinked network topographies. For the shape memory studies to verify the stability of the shape changeability, first, the sample with " $U$ " bent-shape was flattened at temperature above $T_{g}$, and then it was cooled below $T_{g}$ to fix the temporary flat shape of the film. Afterward, the film was transferred to a heating plate with a temperature of around $180{ }^{\circ} \mathrm{C}\left(\mathrm{T}_{\mathrm{g}}\right)$ to promote the recovery of the "U" bent-shape (permanent shape after reshaping), the recovery ratio was around 99\% (Figure S2). The stability of the reshaped film was confirmed in a range of temperature between 25 to $180^{\circ} \mathrm{C}$.

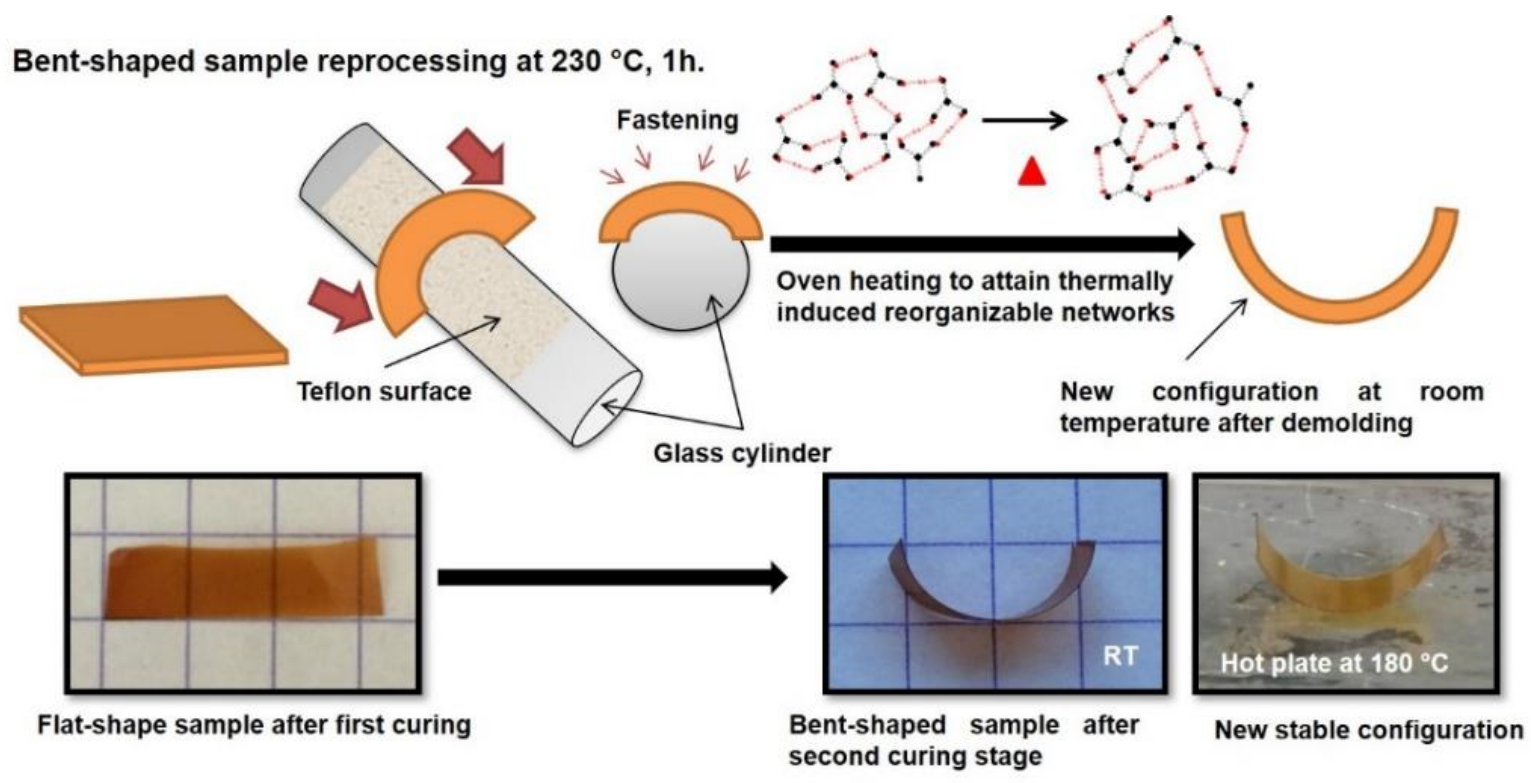

Figure 5. Thermal bent-shaped processing and photograph of the initial and final sample. 
For comparison purposes, a flat film of TEEP:DDS without dynamic properties was reshaped with the same procedure. In this case, the film totally recovered the original flat shape at temperatures around the $T_{g}$ of the system (Figure S3), corroborating that the covalent crosslinked network topographies did not changed and the new "U" bent-shape can only be temporarily fixed at temperatures below the $\mathrm{T}_{\mathrm{g}}$. Another shaping test was carried out by hot pressing fully cured specimens of TEEP:DSA and TEEP:DDS in order to form a thinner film. It was observed that just the partially biobased epoxy containing the dynamic crosslinker was able to be reshaped (Figure S4) while the partially biobased epoxy containing the non-reversible crosslinker was reduced to dust after the shaping test (Figure S5). In this sense, the occurrence of macroscopic flow at high temperature, observed in the thermal stress relaxation test, due to the novel dynamic properties arising from the disulphide exchange reactions is a potential strategy to confer reprocessable characteristics to biobased thermosetting polymers.

\section{Macroscopic thermal self-healing test of partially biobased epoxy system}

To show the ability of developed partially biobased epoxies containing dynamic crosslinker to be repaired by thermal treatment and as result to increase their efficient lifetime, a scratched specimen was heated at $230{ }^{\circ} \mathrm{C}$, a temperature above its $\mathrm{T}_{\alpha}$ or activation temperature, under pressure-free condition (Figure 6). 


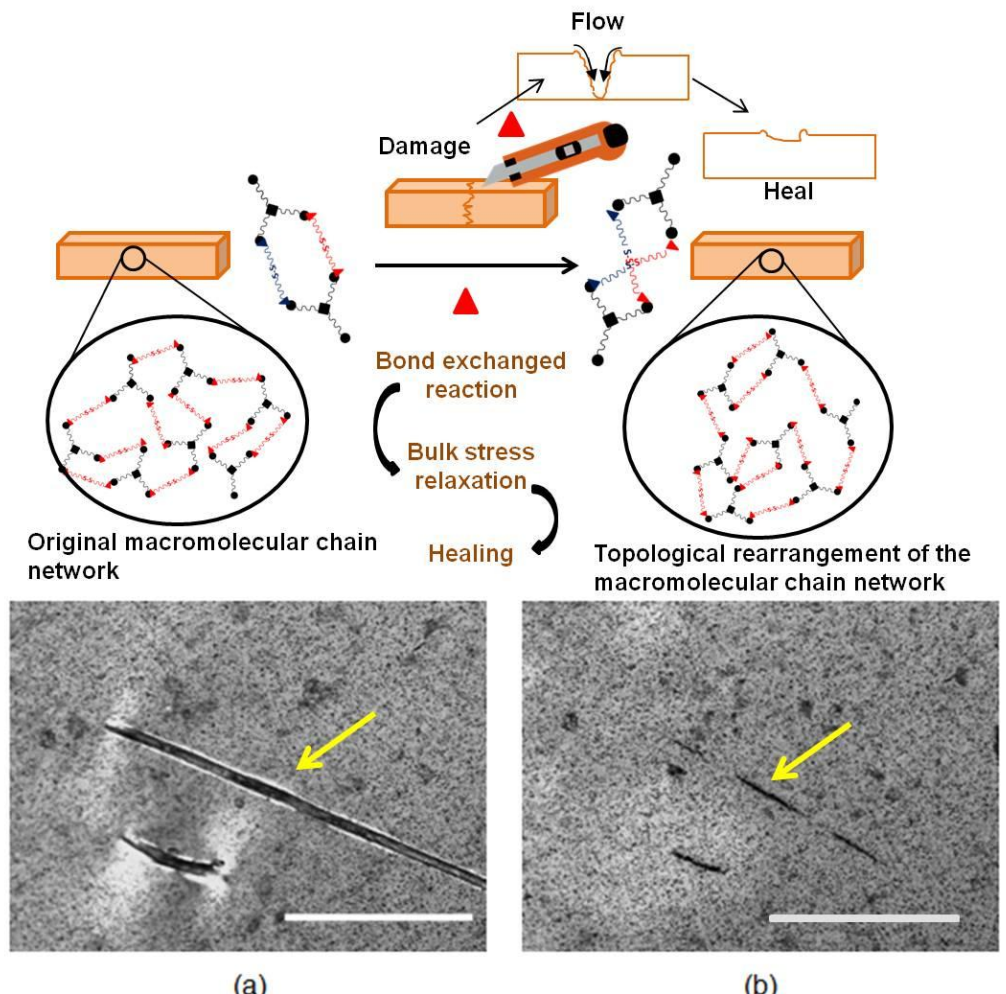

(a)

(b)

Figure 6. Thermal self-healing of TEEP:DSA under stress-free condition. The appearance of the crack depending of repairing time was analyzed at the same site in the sample surface: (a) before and (b) after treatment. Scale bar of OM images $=500 \mu \mathrm{m}$.

This treatment stimulates the softening of the polymer by means of the exchange reaction of disulfide bonds to re-joint the cracked surfaces through the development of new covalent bonds at the interface of the damage surface. As can be seen from OM evaluation (Figure 6), a scratched TEEP:DSA surface shows that the crack gradually disappear when it was heated at $230^{\circ} \mathrm{C}$ during $60 \mathrm{~min}$, indicating the excellent repairing potentials of these novel biobased epoxies. On the contrary, a scratched TEEP:DDS surface did not show self-healing behavior (Figure S6). Corroborating that the softening and welding observed for TEEP:DSA was possible because the disulfide bonds exchange reaction at high temperatures. 


\section{Recycling test of partially biobased epoxy systems}

Here, we demonstrated that fragmented pieces of TEEP:DSA can be potentially welded by a simple hot pressing process at $230{ }^{\circ} \mathrm{C}$ to form a new manufactured material. In addition, the two re-connected pieces presented a good adhesion after manual bending (Figure 7). For comparison purpose, fragmented pieces of TEEP:DDS were submitted to the same recycling process as TEEP:DSA. Nevertheless, it was observed that after treatment the biobased epoxy cured with the non-reversible crosslinker was completely cracked in small pieces (Figure S7). This result confirms that the introduction of dynamic properties in the partially biobased epoxy permit the welding of the two surfaces because novel crosslinked bonds can be created across the interface (bridges) of the pieces when they are brought into contact by hot pressing. This welding capability of TEEP:DSA by hot pressing without the need of an external adhesive can allow promising recycling applications by transforming its plastic waste to potential raw materials.
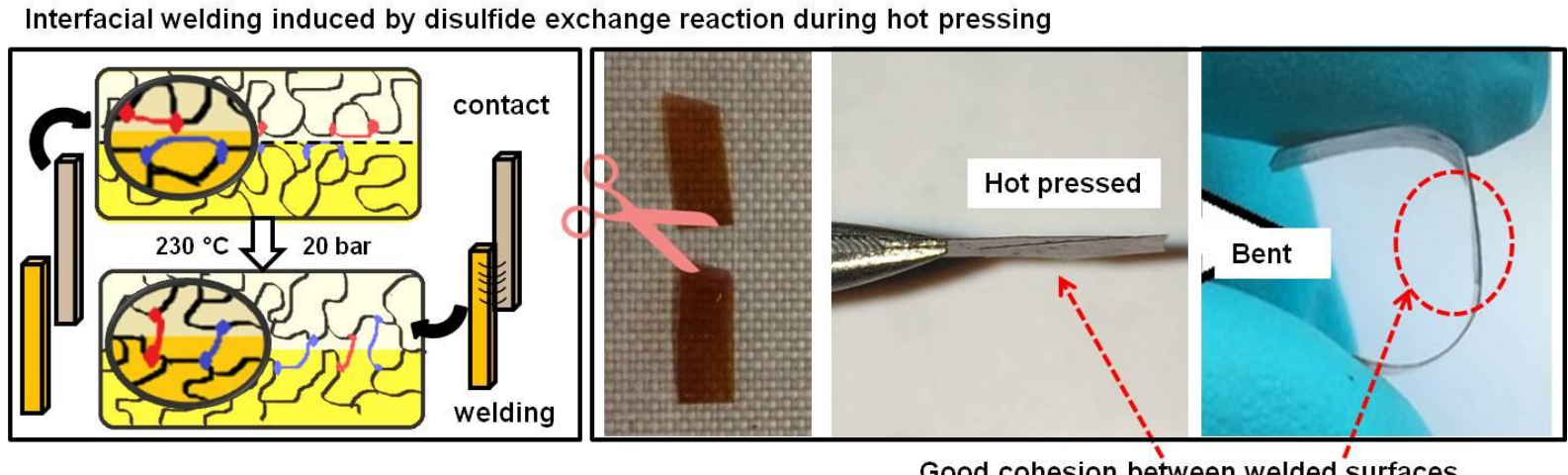

Good cohesion between welded surfaces

Figure 7. Cutting (a) and welding by hot pressing of TEEP:DSA at $230^{\circ} \mathrm{C}$ (b). The sample was manually bent to show the good cohesion between the welded pieces (c).

\section{Conclusions}

In this work we successfully synthesized a sustainable dynamic thermoset with high renewable carbon content based on epoxidized eugenol oil crosslinked with an aromatic diamine containing 
disulfide functional groups. The dynamic eugenol-derived epoxy, TEEP:DSA, revealed comparable stiffness and higher $\mathrm{T}_{\mathrm{g}}$ values than that fossil-based DGEBA. Thermal stress relaxation of TEEP:DSA confirmed the associative crosslink exchange reactions by means of disulfide bonds rearrangement at high temperatures.

It was demonstrated that the proposed strategy of integrating dynamic covalent crosslink in the eugenol-derived epoxy provides highly promising reshaping, self-healing and recycling capabilities. Such a sum of properties is not obtained with conventional thermosets, suggesting a way to increase eugenol-based epoxies lifetime and prevent their waste disposal into the environment. As result, contribute achieving the EU Product Policy Framework of the Circular Economy targets.

Dynamic networks based on eugenol-derived epoxies are very interesting for sustainable fields in e.g., coating and structural systems, for a large range of applications such as transportation, aerospace and building. However, the applicability of TEEP:DSA needs to be now fully demonstrated in real situations by the quantitative evaluation of the recycling and self-healing efficiency in terms of its mechanical properties after several processing cycles.

\section{The following files are available free of charge.}

Supporting Information (PDF)

\section{Corresponding Authors}

*†Connie Ocando and *Luc Avérous

connie.ocando@polymat.eu, luc.averous@unistra.fr

\section{Present Addresses}


$\dagger$ POLYMAT and Polymer Science and Technology Department, University of the Basque Country (UPV/EHU), Paseo Manuel de Lardizabal 3, Donostia-San Sebastian, 20018, Spain.

\section{Credit authorship contribution statement}

Connie Ocando: Conceptualization, Methodology, Validation, Formal analysis, Investigation, Writing - original draft, Visualization, Writing - review \& editing. Yvan Ecochard: Methodology, Investigation, Writing - review \& editing Mélanie Decostanzi: Methodology, Investigation, Writing - review \& editing, Writing - review \& editing. Sylvain Caillol: Resources, Supervision, Writing - review \& editing. Luc Avérous: Resources, Conceptualization, Supervision, Writing - review \& editing, Funding acquisition.

\section{Conflict of interest}

The authors declare that they have no known competing financial interests or personal relationships that could have appeared to influence the work reported in this paper.

\section{Data Availability Statement}

The raw/processed data required to reproduce these findings cannot be shared at this time as the data also forms part of an ongoing study.

\section{REFERENCES}

[1] J. P. Pascault, H. Sautereau, J. Verdu, R. J. Williams in Thermosetting polymers, Vol. 477, New York: Marcel Dekker, 2002.

[2] Auvergne, R., Caillol, S., David, G., Boutevin, B., \& Pascault, J. P. (2013). Biobased thermosetting epoxy: present and future. Chemical reviews, 114(2), 1082-1115.

[3] Rowan, S. J., Cantrill, S. J., Cousins, G. R., Sanders, J. K., \& Stoddart, J. F. (2002). Dynamic covalent chemistry. Angewandte Chemie International Edition, 41(6), 898-952. 
[4] Jin, Y., Yu, C., Denman, R. J., \& Zhang, W. (2013). Recent advances in dynamic covalent chemistry. Chemical Society Reviews, 42(16), 6634-6654.

[5] Zou, W., Dong, J., Luo, Y., Zhao, Q., \& Xie, T. (2017). Dynamic covalent polymer networks: from old chemistry to modern day innovations. Advanced Materials, 29(14), 1606100.

[6] Montarnal, D., Capelot, M., Tournilhac, F., \& Leibler, L. (2011). Silica-like malleable materials from permanent organic networks. Science, 334(6058), 965-968.

[7] M. Capelot, M. M. Unterlass, F. Tournilhac and L. Leibler, ACS Macro Letters, 2012, 1, 789-792.

[8] M. Capelot, D. Montarnal, F. Tournilhac and L. Leibler, J. Am. Chem. Soc., 2012, 134, 7664-7667.

[9] Denissen, W., Winne, J. M., \& Du Prez, F. E. (2016). Vitrimers: permanent organic networks with glass-like fluidity. Chemical science, 7(1), 30-38.

[10] Fortman, D. J., Brutman, J. P., De Hoe, G. X., Snyder, R. L., Dichtel, W. R., \& Hillmyer, M. A. (2018). Approaches to sustainable and continually recyclable cross-linked polymers. ACS Sustainable Chemistry \& Engineering, 6(9), 11145-11159.

[11] Chabert, E., Vial, J., Cauchois, J. P., Mihaluta, M., \& Tournilhac, F. (2016). Multiple welding of long fiber epoxy vitrimer composites. Soft Matter, 12(21), 4838-4845.

[12] Röttger, M., Domenech, T., van der Weegen, R., Breuillac, A., Nicolaÿ, R., \& Leibler, L. (2017). High-performance vitrimers from commodity thermoplastics through dioxaborolane metathesis. Science, 356(6333), 62-65.

[13] Dhers, S., Vantomme, G., \& Avérous, L. (2019). A fully bio-based polyimine vitrimer derived from fructose. Green Chemistry, 21(7), 1596-1601.

[14] Altuna, F. I., Hoppe, C. E., \& Williams, R. J. J. (2018). Epoxy vitrimers: the effect of transesterification reactions on the network structure. Polymers, 10(1), 43.

[15] Rekondo, A.; Martin, R.; Ruiz De Luzuriaga, A.; Cabanero, G.; Grande, H. J.; Odriozola, I. Catalyst-Free Room-Temperature Self-Healing Elastomers Based On Aromatic Disulfide Metathesis. Mater. Horiz. 2014, 1, 237-240.

[16] Lei, Z. Q.; Xiang, H. P.; Yuan, Y. J.; Rong, M. Z.; Zhang, M. Q. Room-Temperature Self-Healable and Remoldable Cross-Linked Polymer Based on the Dynamic Exchange of Disulfide Bonds. Chem. Mater. 2014, 26, 2038-2046.

[17] Ruiz De Luzuriaga, A.; Matxain, J. M.; Ruiperez, F.; Martin, R.; Asua, J. M.; Cabanero, G.; Odriozola, I. Transient Mechanochromism in Epoxy Vitrimer Composites Containing Aromatic Disulfide Crosslinks. J. Mater. Chem. C 2016, 4, 6220-6223.

[18] Wang, Z.; Tian, H.; He, Q.; Cai, S. Reprogrammable, Reprocessible, and Self-Healable Liquid Crystal Elastomer with Exchangeable Disulfide Bonds. ACS Appl. Mater. Interfaces 2017, 9, 33119-33128.

[19] Zhou, F.; Guo, Z.; Wang, W.; Lei, X.; Zhang, B.; Zhang, H.; Zhang, Q. Preparation of Self-Healing, Recyclable Epoxy Resins and Low-Electrical Resistance Composites Based On Double-Disulfide Bond Exchange. Compos. Sci. Technol. 2018, 167, 79-85. 
[20] Imbernon, L.; Oikonomou, E. K.; Norvez, S.; Leibler, L. Chemically Crosslinked Yet Reprocessable Epoxidized Natural Rubber Via Thermo-Activated Disulfide Rearrangements. Polym. Chem. 2015, 6, 4271-4278.

[21] de Luzuriaga, A. R., Martin, R., Markaide, N., Rekondo, A., Cabañero, G., Rodríguez, J., \& Odriozola, I. (2016). Epoxy resin with exchangeable disulfide crosslinks to obtain reprocessable, repairable and recyclable fiber-reinforced thermoset composites. Materials Horizons, 3(3), 241-247.

[22] Zhou, F., Guo, Z., Wang, W., Lei, X., Zhang, B., Zhang, H., \& Zhang, Q. (2018). Preparation of self-healing, recyclable epoxy resins and low-electrical resistance composites based on double-disulfide bond exchange. Composites Science and Technology, 167, 79-85.

[23] Chen, M., Zhou, L., Wu, Y., Zhao, X., \& Zhang, Y. (2019). Rapid stress relaxation and moderate temperature of malleability enabled by the synergy of disulfide metathesis and carboxylate transesterification in epoxy vitrimers. ACS Macro Letters, 8(3), 255-260.

[24] Turkenburg, D. H., \& Fischer, H. R. (2015). Diels-Alder based, thermo-reversible crosslinked epoxies for use in self-healing composites. Polymer, 79, 187-194.

[25] Kuang, X., Liu, G., Dong, X., \& Wang, D. (2016). Triple-shape memory epoxy based on Diels-Alder adduct molecular switch. Polymer, 84, 1-9.

[26] Zhang, Z. P., Rong, M. Z., \& Zhang, M. Q. (2018). Polymer engineering based on reversible covalent chemistry: A promising innovative pathway towards new materials and new functionalities. Progress in Polymer Science, 80, 39-93.

[27] Meier, M. A., Metzger, J. O., \& Schubert, U. S. (2007). Plant oil renewable resources as green alternatives in polymer science. Chemical Society Reviews, 36(11), 1788-1802.

[28] Jaillet, F., Darroman, E., Ratsimihety, A., Auvergne, R., Boutevin, B., \& Caillol, S. (2014). New biobased epoxy materials from cardanol. European Journal of Lipid Science and Technology, 116(1), 63-73.

[29] Voirin, C., Caillol, S., Sadavarte, N. V., Tawade, B. V., Boutevin, B., \& Wadgaonkar, P. P. (2014). Functionalization of cardanol: towards biobased polymers and additives. Polymer Chemistry, 5(9), 3142-3162.

[30] Gerbase, A. E., Petzhold, C. L., \& Costa, A. P. O. (2002). Dynamic mechanical and thermal behavior of epoxy resins based on soybean oil. Journal of the American Oil Chemists' Society, 79(8), 797-802.

[31] Faye, I., Decostanzi, M., Ecochard, Y., \& Caillol, S. (2017). Eugenol bio-based epoxy thermosets: from cloves to applied materials. Green Chemistry, 19(21), 5236-5242.

[32] Liu, T., Hao, C., Wang, L., Li, Y., Liu, W., Xin, J., \& Zhang, J. (2017). Eugenol-derived biobased epoxy: shape memory, repairing, and recyclability. Macromolecules, 50(21), 8588-8597.

[33] Liu, T., Hao, C., Zhang, S., Yang, X., Wang, L., Han, J., .. \& Zhang, J. (2018). A selfhealable high glass transition temperature bioepoxy material based on vitrimer chemistry. Macromolecules, 51(15), 5577-5585. 
[34] Wan, J., Zhao, J., Gan, B., Li, C., Molina-Aldareguia, J., Zhao, Y., Pan, Y. T. \& Wang, D. Y. (2016). Ultrastiff biobased epoxy resin with high Tg and low permittivity: from synthesis to properties. ACS Sustainable Chemistry \& Engineering, 4(5), 2869-2880.

[35] Yang, X., Guo, L., Xu, X., Shang, S., \& Liu, H. (2020). A fully bio-based epoxy vitrimer: Self-healing, triple-shape memory and reprocessing triggered by dynamic covalent bond exchange. Materials \& Design, 186, 108248.

[36] Ma, Z., Wang, Y., Zhu, J., Yu, J., \& Hu, Z. (2017). Bio- based epoxy vitrimers: Reprocessibility, controllable shape memory, and degradability. Journal of Polymer Science Part A: Polymer Chemistry, 55(10), 1790-1799.

[37] Wan, J., Gan, B., Li, C., Molina-Aldareguia, J., Kalali, E. N., Wang, X., \& Wang, D. Y. (2016). A sustainable, eugenol-derived epoxy resin with high biobased content, modulus, hardness and low flammability: synthesis, curing kinetics and structure-property relationship. Chemical Engineering Journal, 284, 1080-1093.

[38] Alessi, S., Caponetti, E., Güven, O., Akbulut, M., Spadaro, G., \& Spinella, A. (2015). Study of the curing process of DGEBA epoxy resin through structural investigation. Macromolecular Chemistry and Physics, 216(5), 538-546.

[39] Van Herck, N., \& Du Prez, F. E. (2018). Fast healing of polyurethane thermosets using reversible triazolinedione chemistry and shape-memory. Macromolecules, 51(9), 34053414. 